\title{
A conceptual model of the influence of stress on female reproduction
}

\author{
Hilary Dobson, Sarvpreet Ghuman, Sushil Prabhakar and Robert Smith \\ Department of Veterinary Clinical Science, University of Liverpool, Leahurst, Neston, \\ Wirral CH64 7TE, UK
}

\begin{abstract}
Intriguingly, similar neurotransmitters and nuclei within the hypothalamus control stress and reproduction. $\mathrm{GnRH}$ neurone recruitment and activity is regulated by a balance between stimulation, suppression and permissiveness controlled by noradrenaline, neuropeptide $Y$ and serotonin from the brain stem, impact from glutamate in the medial preoptic area and neuropeptide $Y$ in the arcuate nucleus, in opposition to the restraining influences of $\gamma$-aminobenzoic acid within the medial preoptic area and opioids from the arcuate nucleus. Stress also activates neuropeptide $Y$ perikarya in the arcuate nucleus and brain stem noradrenaline neurones. The latter project either indirectly, via the medial preoptic area, or directly to the paraventricular nucleus to release corticotrophin releasing hormone $(\mathrm{CRH})$ and arginine vasopressin (AVP). Within the medial preoptic area, GnRH neurones synapse with $\mathrm{CRH}$ and AVP axons. Stimulation of $\mathrm{CRH}$ neurones in the paraventricular nucleus also activates $\gamma$-aminobenzoic acid and opioid neurones in the medial preoptic area and reduces $\mathrm{GnRH}$ cell recruitment, thereby decreasing $\mathrm{GnRH}$ pulse frequency. Oestradiol enhances stress-induced noradrenaline suppression of LH pulse frequency but when applied in the paraventricular nucleus or brain stem, and not in the medial preoptic area or arcuate nucleus. The importance of CRH and AVP in the medial preoptic area needs confirming in a species other than the rat, which uses adrenal activation to time the onset of the GnRH surge. Another stress-activated pathway involves the amygdala and bed of the nucleus stria terminalis, which contain $\mathrm{CRH}$ neurones and accumulate $\gamma$-aminobenzoic acid during stress.
\end{abstract}

Transmitting genes to the next generation is the most important activity of any organism. However, when conditions are not optimal, it is prudent to suspend reproduction until the environment is more favourable. In general, stress-induced adrenal stimulation delays or even inhibits the preovulatory GnRH-LH surge. In female rats, stress-reproduction interactions are complex because of a timing mechanism that increases adrenal gland activity before the GnRH-LH surge on the afternoon of pro-oestrus. Hence in rats, adrenal stimulation is normally associated with the facilitation of surge initiation. Therefore, comparisons with other species that do not present this complication are advantageous. The hypothalamus is larger in sheep than it is in rats and so anatomical targeting studies are more precise, and it is possible to collect frequent hypophyseal portal samples to delineate precise patterns of $\mathrm{GnRH}-\mathrm{LH}$ secretion. Such techniques can be used to identify the critical link(s) between the mechanisms controlling reproduction and

Email: hdobson@liv.ac.uk stress responses. For example, in the context of fertility, it is pertinent to know the importance of stress-induced changes in $\mathrm{GnRH}-\mathrm{LH}$ pulsatility, oestradiol profiles and the precise timing of events leading up to the LH surge.

Many of the links between reproduction and stresscontrol systems involve neurotransmitters. These compounds convey messages between neurones and are crucial for the control of correct hypothalamic GnRH secretion in different reproductive phases. Individual neurotransmitters are often stimulatory (for example, noradrenaline and neuropeptide Y), whereas other neurotransmitters usually exert inhibitory influence (for example, opioids and gamma amino butyric acid $(G A B A))$. Neurotransmitters are secreted on one side of an interneurone interface (synapse) and engage with specific receptors on the opposite neurone. Furthermore, some neurones have an auto-inhibitory system, which means that presynaptic receptors are activated so that when a neurotransmitter is released, it can act back on the secreting cell and inhibit its own production.

The present article reviews recent knowledge concerning the normal regulation of the systems controlling 


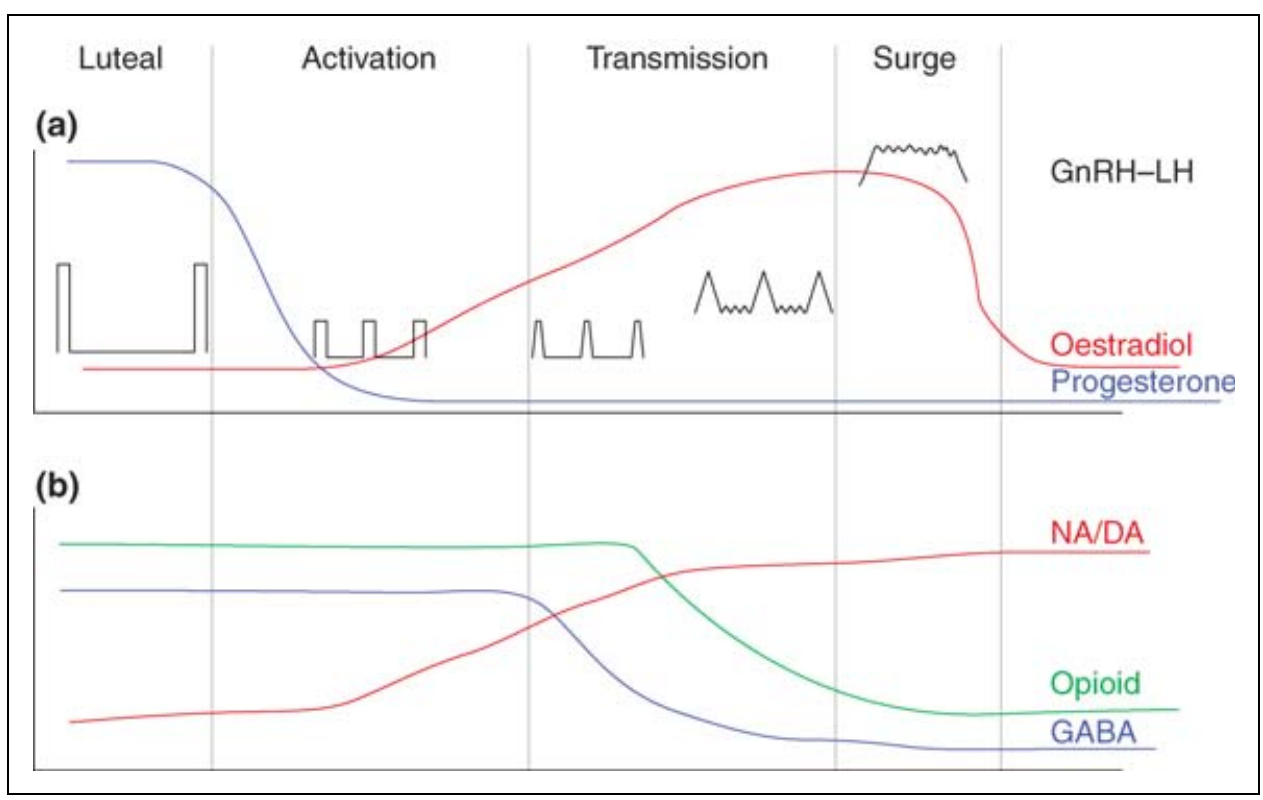

Fig. 1. (a) Luteal and oestradiol-induced activation and transmission phases before the surge secretion of GnRH (derived from Evans et al., 1995, 1997) in ewes. (b) Proposed changes in neurotransmitter influence during normal GnRH secretion in ewes. DA: dopamine; GABA: gamma amino butyric acid; NA: noradrenaline.

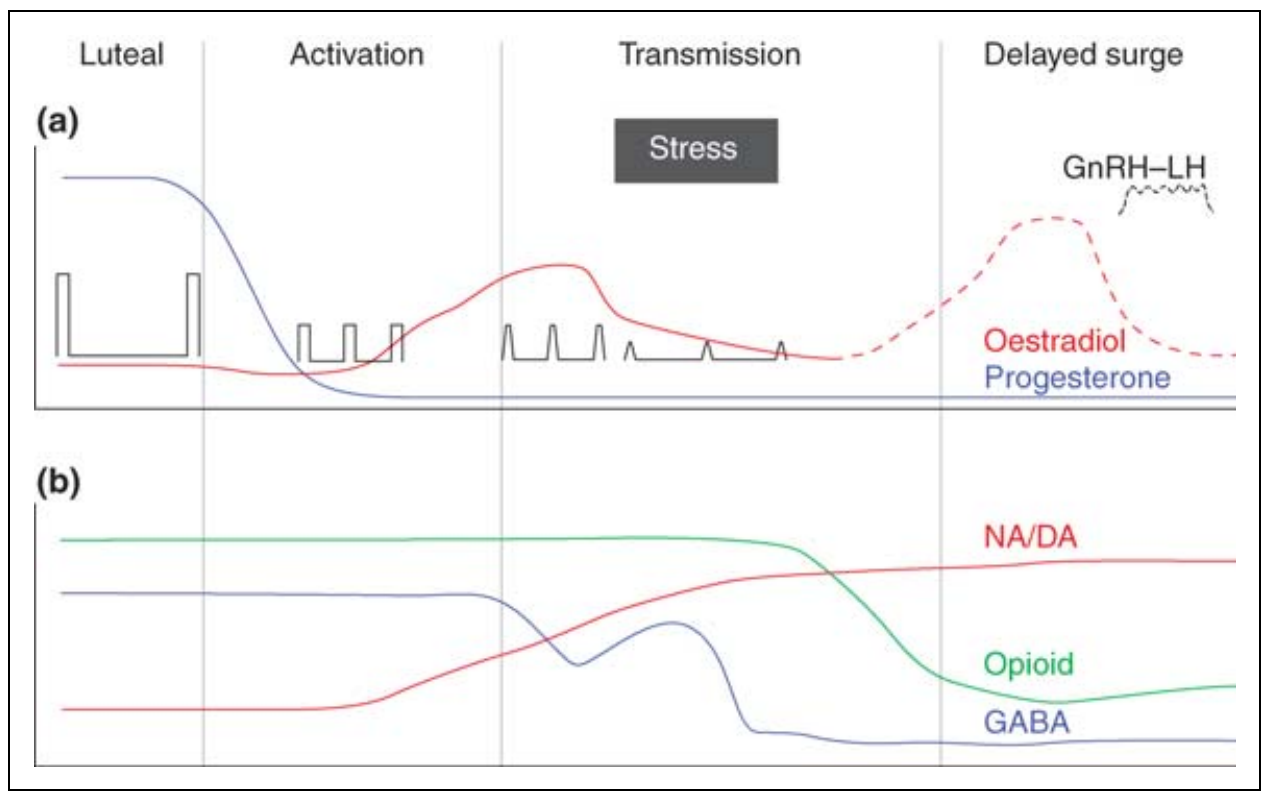

Fig. 2. (a) Changes in the endocrine milieu caused by stress in ewes (derived from Dobson and Smith, 1998, 2000). (b) Proposed changes in neurotransmitter influence during stress-induced delayed $\mathrm{GnRH}$ secretion in ewes. DA: dopamine; GABA: gamma amino butyric acid; NA: noradrenaline.

reproduction or stress (the hypothalamus-pituitaryovary axis (HPO) and the hypothalamus-pituitaryadrenal gland axis (HPA)), and then examines HPO and HPA inter-relationships (in particular, the importance of oestradiol sensitivity) before placing the whole theme in the context of human and animal fertility.

\section{Control of normal reproductive hormone profiles}

Normal endocrine changes in female sheep during the follicular phase (Fig. 1) contrast with those imposed by stress (Fig. 2). The pivotal roles of different parts of the brain and hypothalamus in controlling and maintaining normal hormone profiles have been reviewed by 
Herbison (1997, 1998) and Smith and Jennes (2001). Pulsatile activity is an essential intrinsic property of hypothalamic $\mathrm{GnRH}$ neurones and the intricate balance between $\mathrm{GnRH}$ synthesis and release is important to ensure that $\mathrm{GnRH}$ neurones are in a state of constant readiness to respond to changes in the environment (Vazquez-Martinez et al., 2001). Regulation of pulsatile GnRH secretion probably involves interneurones because GnRH neurones have very few receptors for hormonal steroids. In brief, the most important site for regulation of $\mathrm{GnRH}$ secretion is the $\mathrm{GnRH}$ perikarya in the medial preoptic area of the hypothalamus (MPOA). There is still uncertainty concerning modulation of $\mathrm{GnRH}$ release at the other end of the axons in the median eminence (ME); similarly, debate continues over the existence of separate systems for pulsatile and surge secretion (Herbison, 1998). However, we propose that precisely controlled $\mathrm{GnRH}$ pulse frequency and amplitude are essential prerequisites for the timely production of appropriate $\mathrm{GnRH}-\mathrm{LH}$ surge secretion. Consequently, disruption of pulsatile secretion will have deleterious effects on the production of a normal surge and will therefore reduce fertility.

\section{Influence of the brain stem on GnRH neurones in the MPOA and modulation by oestradiol}

There is a delicate balance between the positive and negative influences of oestradiol, noradrenaline and GABA in the control of GnRH perikarya in the MPOA (Figs 3 and 4). From areas within the brain stem, almost all noradrenergic cells with oestradiol receptors in regions A1 (ventrolateral medulla; VLM) or A2 (nucleus of the tractus solitarius; NTS) project axons to the MPOA to synapse with $\mathrm{GnRH}$ perikarya to stimulate $\mathrm{GnRH}$ secretion (Herbison, 1998; Scott et al., 1999). Axons from noradrenaline cells in regions $\mathrm{A} 1$ or $\mathrm{A} 2$ also directly or indirectly activate GABA perikarya in the MPOA to suppress GnRH secretion. Hence, there is a balance between brain stem stimulation and suppression of GnRH secretion from the MPOA (Herbison, 1998). All GABA-ergic cells that synapse with $\mathrm{GnRH}$ neurones have steroid receptors and are extremely sensitive to these hormones. In the luteal phase, progesterone increases GABA tone and hence maintains very low frequency square-wave $\mathrm{GnRH}$ pulses (Fig. 1a). During the very early follicular phase in the presence of declining peripheral progesterone concentrations, oestradiol inhibits the autoinhibitory system of GABA cells so increased GABA concentrations are maintained in the MPOA, thereby maintaining suppression of $\mathrm{GnRH}-\mathrm{LH}$ secretion (Fig. 1). Longer exposure to oestradiol during the mid-follicular phase in sheep increases noradrenaline in the MPOA culminating maximally in the late follicular phase just before the GnRH-LH surge (Robinson et al., 1991). Subsequent uncoupling of noradrenaline stimulation of GABA cells follows (by an unidentified but crucial mechanism) which

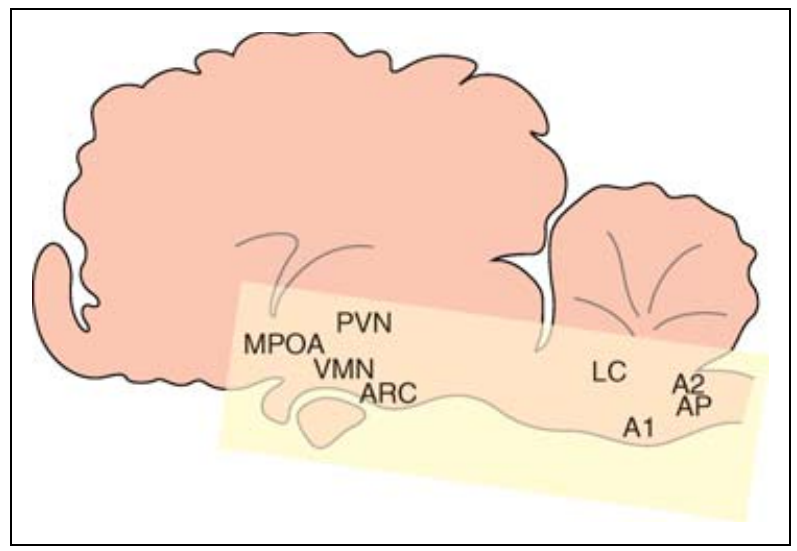

Fig. 3. Location and influence of numerous neuronal nuclei in the brain of the ewe that regulate $\mathrm{GnRH}$ and corticotrophin-releasing hormone $(\mathrm{CRH})$-arginine vasopressin (AVP) secretion, indicating the spatial relationship between regions of the hypothalamus (medial preoptic area (MPOA), ventral medial nucleus (VMN) and arcuate nucleus (ARC) of the medial basal hypothalamus)) and the brain stem ( $\mathrm{A} 1$ and $\mathrm{A} 2$ regions, the area postrema (AP) and the locus coeruleus (LC)). PVN: paraventricular nucleus.

removes the suppression by GABA. The decrease in GABA influence and increase in noradrenaline influence lead to a surge in GnRH secretion (Herbison, 1998) and explain earlier observations in sheep that noradrenaline administered in the late follicular phase stimulates $\mathrm{LH}$ secretion, whereas antagonists block the LH surge (Narayana and Dobson, 1979). It must also be noted that recent studies of the MPOA using electron microscopy revealed that receptors for noradrenaline in the $\mathrm{GnRH}$ cell membrane are not very close to $\mathrm{GnRH}$ synapses in regions $A 1$ and $A 2$. Thus, there may be reliance on asynaptic release of noradrenaline followed by diffusion to receptors within the $\mathrm{GnRH}$ neurone before cell activation (Smith and Jennes, 2001). Nevertheless, the activities of GABA and GnRH perikarya in the MPOA are clearly modulated by brain stem noradrenaline neurones in response to changes in oestradiol concentration.

\section{Influence of the medial basal hypothalamus on $\mathrm{GnRH}$ neurones in the MPOA and modulation by the brain stem}

In addition to control by the brain stem, GnRH perikarya in the MPOA (Fig. 4) are also under the influence of afferent neurones from the arcuate nucleus (ARC) and ventromedial hypothalamic nucleus (VMN) (collectively known as the medial basal hypothalamus $(\mathrm{MBH})$ ). Opioid perikarya in the ARC (few of which have oestradiol receptors) project axons to the MPOA and synapse directly with GnRH cells (Goubillon et al., 1999, 2002). Opioids from the ARC, noradrenaline from the brain stem and GABA neurones from within the MPOA may be involved in synchronizing the firing of different groups of neurones in the GnRH network 


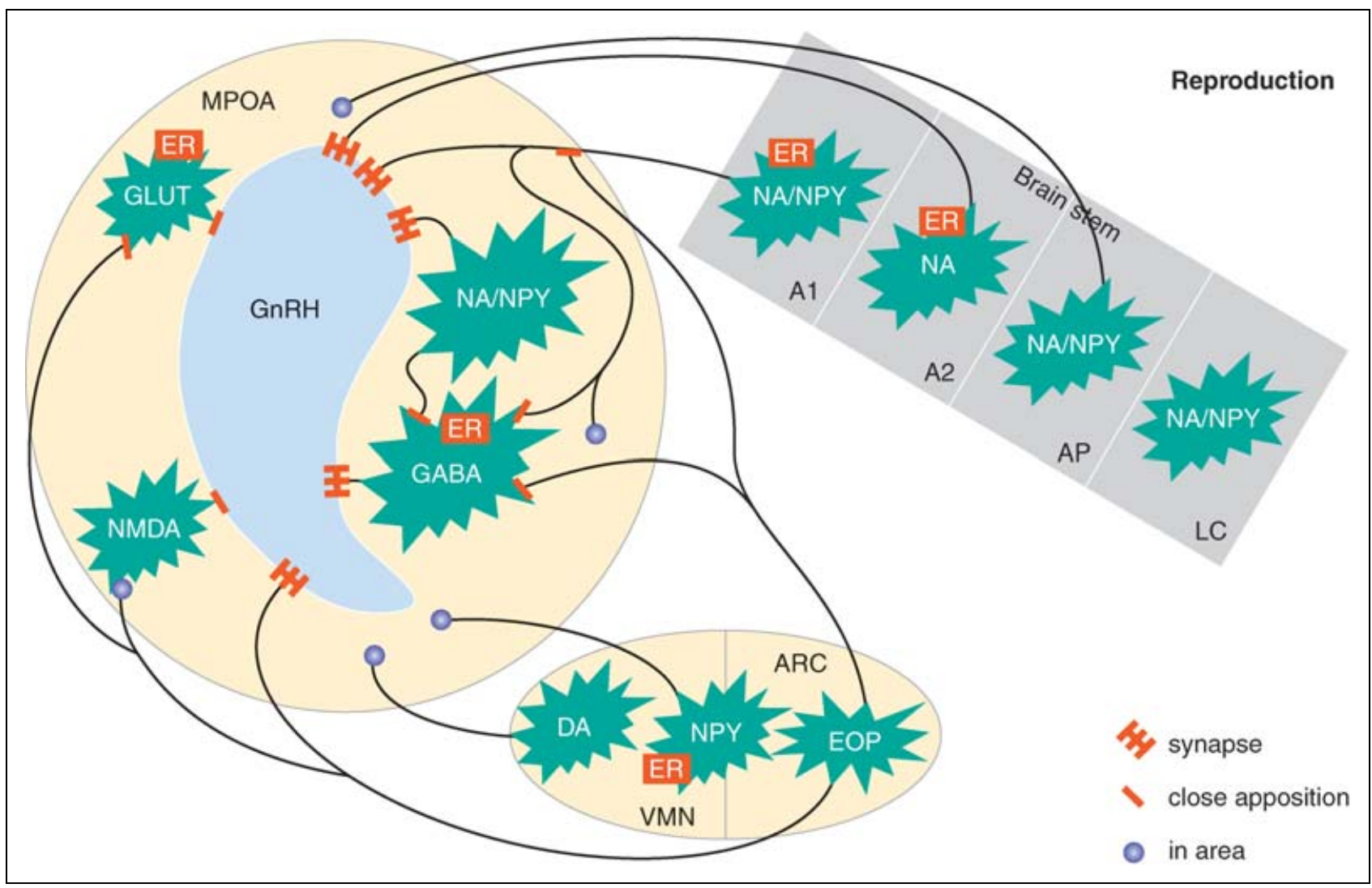

Fig. 4. Schematic representation of the location and influence of numerous neurones that regulate GnRH secretion (data amalgamated from observations in ewes and rats). The comma-shaped object represents a GnRH neurone; the grey shaded rectangular areas denote different portions of the brain stem (A1 and A2 regions, the area postrema (AP) and the locus coeruleus (LC)) and the yellow areas indicate regions in the hypothalamus (medial preoptic area (MPOA), ventral medial nucleus (VMN) and the arcuate nucleus (ARC) of the medial basal hypothalamus). The blast shapes represent neurones containing specific neurotransmitters (noradrenaline (NA), neuropeptide Y (NPY), glutamate (GLUT), N-methyl-D-aspartate (NMDA), gamma amino butyric acid (GABA), endogenous opioid (EOP) and dopamine (DA)). The presence of receptors for oestradiol (ER) is indicated on appropriate neurones. The interlinking black lines between areas of the brain represent known direct axons. Identified synapses are shown by red striped bars, whereas close apposition between axons and perikarya is represented by plain red bars. If direct intercellular contact remains to be proven, the axons end in an area with a purple circle. There are axons from GnRH cells to the median eminence but these have been omitted here for clarity.

(Robinson et al., 1991; Goodman et al., 1995, 1996). It is not certain how many of the total of $2000 \mathrm{GnRH}$ neurones discharge at any one time either for each $\mathrm{GnRH}$ pulse or during the preovulatory surge. However, it has been hypothesized that different interneurones alter secretion rates of various groups of $\mathrm{GnRH}$ axons and collaborate in the co-ordinated cascade of events that culminates in surge secretion (Karsch and Evans, 1996). Within the MPOA, opioids regulate $\mathrm{GnRH}$ secretion (Goodman et al., 1995) but as there are few endogenous opioid (EOP) receptors on GnRH cells, other interneurones may also be involved (Thind and Goldsmith, 1988). Opioid neurones also synapse with noradrenaline interneurones in the MPOA. It is of interest that a decrease in opioid activity just before the LH surge occurs synchronously with the uncoupling of noradrenaline influence on GABA cells in the MPOA (Herbison, 1998).
Thus, the $\mathrm{MBH}$ can modify the brain stem control of $\mathrm{GnRH}$ perikarya. Electrodes placed within the ARC-ME area have detected increased neuronal electrical activity after the withdrawal of progesterone in female goats. However, the frequency of electrical impulses decreases just before and during the GnRH surge (Takeuchi et al., 1997).

There are other examples of $\mathrm{MBH}$ modulation of $\mathrm{GnRH}$ neurones in the MPOA. In rats, opioids restrain stimulatory catecholaminergic, glutaminergic and nitric oxide input, and enhance inhibitory GABA (Smith and Jennes, 2001). In addition, dopamine concentrations in the $\mathrm{VMN}$ increase just before the $\mathrm{GnRH}$ surge (Anderson et al., 2001). Perikarya containing neuropeptide $Y$ within the $\mathrm{VMN}-\mathrm{ARC}$ also exert stimulatory influence in the MPOA (Fig. 4); neuropeptide $Y$ is essential for $\mathrm{GnRH}$ surge secretion as central administration of antibodies 
to neuropeptide $\mathrm{Y}$ blocks the $\mathrm{LH}$ surge in rats and sheep (Porter et al., 1993). This effect could be exerted indirectly via influences on GnRH pulse frequency, or directly by interfering with any as yet unidentified 'surge mechanism'. In addition to the neurotransmitter systems already mentioned, approximately $50 \% \mathrm{GnRH}$ cells that activate c-fos during the $\mathrm{LH}$ surge also have glutamate receptors, along with up to $80 \%$ activated $\mathrm{GnRH}$ cells that have N-methyl-D-aspartate (NMDA) receptors (Smith and Jennes, 2001). Clearly, the neuronal control of $\mathrm{GnRH}$ secretion involves complex but orderly interactions between the brain stem, MBH and MPOA.

\section{Working model to explain the generation of the GnRH-LH surge}

An experimental model has been proposed to facilitate closer examination of the temporal sequences leading to the $\mathrm{GnRH}-\mathrm{LH}$ surge in sheep (Evans et al., 1997). Here, the model is elaborated by presenting explanations in terms of the changing influence of neurotransmitters. The resultant concept indicates several possibilities, many of which are based on patchy evidence and remain to be fully tested. In the model, oestradiol implants, inserted into ovariectomized ewes $16 \mathrm{~h}$ after progesterone withdrawal, begin a three-stage surge induction process (Fig. 1). First, there is a signal-reading phase of 5-10 h for activation of oestradiol-sensitive neurones. Second, a signal-processing phase (from 10 to about $18 \mathrm{~h}$ ) when message(s) are transmitted to $\mathrm{GnRH}$ neurones via one or more oestradiol-sensitive interneurones. A third stage involves initiation of $\mathrm{GnRH}$ surge release (from about 18 to $20 \mathrm{~h}$ ). These stages approximate to the gradually merging phases of different $\mathrm{GnRH}$ profiles (Evans et al., 1995).

Initially, there are infrequent $\mathrm{GnRH}-\mathrm{LH}$ pulses (one every $4 \mathrm{~h}$ ) in the progesterone-dominated phase that precedes the insertion of oestradiol implants. In comparison, during the follicular activation phase, pulse frequency increases and pulse amplitude decreases but squarewave GnRH pulses are discrete with barely detectable basal GnRH secretion (Fig. 1a). This pattern occurs in the presence of high GABA and opioid tone with increasing noradrenaline influence (Fig. 1b). During the early transmission phase, GABA influence declines, noradrenaline continues to increase and $\mathrm{GnRH}$ pulses begin to develop a more spike-like triangular shape. In the late transmission phase, within $3-4 \mathrm{~h}$ before surge onset, opioid influence begins to decline, GnRH pulses become more triangular and interpulse $\mathrm{GnRH}$ concentrations increase (Goodman et al., 1995). The final surge initiation phase reveals very high $\mathrm{GnRH}$ concentrations and pulses are difficult to distinguish. Whether the GnRH format changes to continuous high secretion or very rapid pulses is open to debate (Evans et al., 1995). Overall, it is hypothesized that GnRH neurones become progressively desynchronized and surge secretion ensues with all neurones maximally activated and secreting GnRH.

\section{Influence of exposure to progesterone before the follicular phase}

The above neuroendocrine observations might explain the balance between the effects of oestradiol and progesterone (although the following hypotheses do require further rigorous testing). In the early follicular phase of intact ewes, there is a gradual decline in progesterone after the onset of luteolysis simultaneous with a gradual increase in oestradiol stimulated from follicles by increasing LH pulse frequency. During this phase, progesterone acts via GABA neurones to hold $\mathrm{GnRH}$ pulse frequency in check in the face of increasing oestradiol stimulatory influence (Robinson et al., 1991). Even after removal from the peripheral circulation, progesterone has long-lasting effects. The classic progesterone receptor blocker, RU486, will advance the LH surge by $9 \mathrm{~h}$ when administered to intact animals even $37 \mathrm{~h}$ after prostaglandin-induced luteolysis (surge onset at $53 \mathrm{~h}$ after luteolysis versus $62 \mathrm{~h}$ in controls; Dobson et al., 2000a). Thus, progesterone modulates the influence of oestradiol.

\section{Early oestradiol action}

When considering further details of the neuronal effects of oestradiol, it is important to recognize that almost all neurones with oestradiol receptors $(70 \%$ of which contain noradrenaline) in the caudal A1 region of the brain stem project to the MPOA (Fig. 4). In addition, $30 \%$ noradrenaline cells in A 1 express c-fos (an early indicator of neuronal activity) within $2 \mathrm{~h}$ of oestradiol treatment (Scott et al., 1999; Rawson and Clarke, 2001). In the same time frame, oestradiol also induces $c$-fos activity in approximately $20 \%$ of neuropeptide $Y$ cells and in a few opioid cells in the VMN. However, most of the activated neurones are of unidentified phenotype (Clarke et al., 2001). Thus, it is hypothesized that, under the influence of oestradiol during the early activation phase, noradrenaline neurones from the brain stem and from within the MPOA initially activate MPOA GABA perikarya. This activation of GABA neurones by noradrenaline, along with the neuropeptide $Y$ and opioid influence of $\mathrm{MBH}$ origin, decrease pulse amplitude and increase pulse frequency (Scott et al., 1992; Smith and Jennes, 2001). It is proposed that, during the transmission phase, GnRH pulses begin to change shape as the effects of GABA gradually diminish (Fig. 1). In the late transmission phase, a decrease in opioid tone further prolongs pulse duration and increases $\mathrm{GnRH}$ secretion between pulses (Goodman et al., 1995; Evans et al., 1997). Eventually, at the onset of the surge, all inhibition is removed. 
Clearly, GnRH secretion is regulated by a balance between stimulation, suppression and permissiveness controlled by noradrenaline from the brain stem, sudden impact from glutamate in the MPOA and neuropeptide $Y$ from the ARC, in opposition to the inhibitory influences of GABA within the MPOA and opioids from the ARC. Furthermore, it is pertinent at this point to note that oestradiol must be administered into the VMN rather than the MPOA to generate an LH surge (Herbison, 1998).

\section{Other roles of oestradiol in generation of the GnRH-LH surge}

Removal of oestradiol implants before initiation of the surge (that is, after only $10 \mathrm{~h}$ exposure) influences neither the timing of surge onset nor the amplitude of the $\mathrm{GnRH}$ surge. However, less $\mathrm{LH}$ is released, indicating that there is a requirement for longer oestradiol priming at the pituitary gland for a full amplitude LH surge (Evans et al., 1997). Oestradiol enhances hypothalamic $\mathrm{GnRH}$ synthesis and pituitary responsiveness to GnRH by increasing $\mathrm{GnRH}$ receptor mRNA, and thus the number of receptors, in gonadotrophes, creating greater stores of LH (Hamernik, 1995; Brooks and McNeilly, 1996; Jimenez-Linman and Rubin, 2001).

In summary, oestradiol has marked effects at the hypothalamus and the pituitary gland to produce regulated GnRH pulses and a normal, appropriately timed LH surge.

\section{Normal HPA endocrine responses to stressors}

Physiological amounts of insulin are required for normal neuronal activity but the sudden exposure to bolus insulin injections will activate the HPA axis, as will many other stressors, for example, transport, restraint or isolation. As part of this response, ACTH release from the pituitary gland is stimulated by activation of perikarya in the hypothalamic paraventricular nucleus (PVN; Figs 3 and 5). The two releasing factors from the PVN, corticotrophin releasing hormone $(\mathrm{CRH})$ and arginine vasopressin (AVP), are secreted from the ME into the hypophyseal portal system to release $\mathrm{ACTH}$ from the pituitary gland but the relative importance of $\mathrm{CRH}$ and AVP is currently controversial (Smith et al., in press). More $\mathrm{CRH}$ than AVP is released in rats, whereas the reverse occurs in sheep. The $\mathrm{CRH}$ : AVP ratio may be governed by the intensity of the stressor, with $\mathrm{CRH}$ predominating after low doses of insulin whereas more AVP is secreted after high doses (Caraty et al., 1990). However, CRH is a more potent stimulator of ACTH secretion than is AVP in sheep (McFarlane et al., 1995). Nevertheless, AVP is required in stress-induced suppression of reproductive activity, as revealed by the ability of AVP antagonists to prevent the suppressive effects of insulin on LH secretion (Heisler et al., 1994).
Influence of the brain stem and MPOA on PVN secretory activity

Higher up the system (Fig. 5), stressors increase the firing rate of regions in the brain stem, particularly noradrenaline-neuropeptide $\mathrm{Y}$ neurones in the $\mathrm{A}$ 1 (VLM), A2 (NTS) and A6 (locus coeruleus; LC) regions. There are synaptic contacts between noradrenalineneuropeptide $\mathrm{Y}$ nerve fibres and $\mathrm{CRH}$ perikarya in the PVN, although there have been no confirmatory retrograde or anterograde double-labelled studies to confirm the location of the perikarya of these axons (Krysiak et al., 1999). In contrast, detailed tracing studies in rats have shown that noradrenaline perikarya send axons from the A1 (VLM) to the MPOA that, in turn, synapse with afferent neurones projecting to the PVN, and that these axons are activated during stress (Kawano and Masuko, 1999, 2000). It is important to establish the significance of $\mathrm{CRH}$ pathway interactions through the MPOA in species other than the rat that do not have an increase in corticoids associated with the GnRH-LH surge.

\section{Involvement of receptors during negative feedback}

A stimulatory role of noradrenaline in the HPA is confirmed by the sustained release of ACTH after prolonged central noradrenaline administration, in contrast to the short-lived ACTH secretion that occurs during exposure to spontaneous stressors. One explanation of these contrasting scenarios could involve immediate activation of a negative feedback system exerted by glucocorticoid receptors on CRH cells in the PVN (Fig. 5). In addition, the hippocampus contains many mineralocorticoid and glucocorticoid receptors and, although there is no direct innervation to the PVN, there are projections from the hippocampus to the ARC and VMN that exert negative feedback on PVN activity. Furthermore, axons from neuropeptide $\mathrm{Y}$ perikarya with glucocorticoid receptors in the ARC project to the PVN. It is reasonable that there should be an efficient negative feedback system in view of the deleterious effects of overstimulation of the HPA, that is, prolongation of enhanced glucose metabolism, altered vascular dynamics and deranged immune responses.

\section{Other pathways modulating PVN secretion}

In addition to a significant role in emotional behaviour and motivation, the rat central nucleus of the amygdala (CeA) also contains many CRH perikarya with efferent pathways to the hypothalamus through the lateral bed nucleus of the stria terminalis (BNST) and onward to the MPOA. Lesions of these tracts lower stress-induced CRH concentrations in the ME (Tellam et al., 2000).

It has been suggested that $\mathrm{CRH}$ is a neurotransmitter as well as a neurohormone (Tellam et al., 2000). CRH injected intracerebroventricularly (i.c.v.) or directly into 


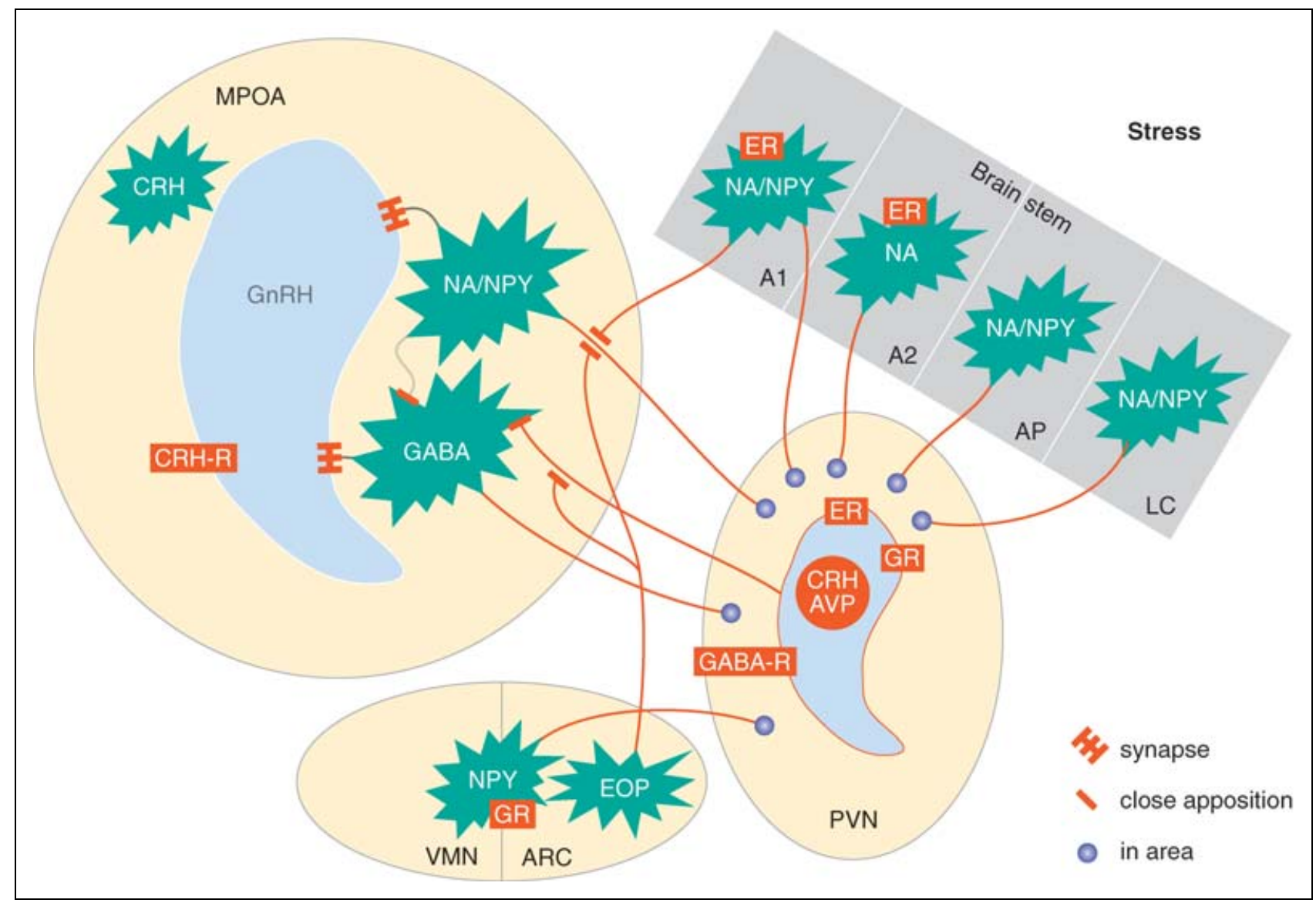

Fig. 5. Schematic representation of the location and influence of numerous neurones that regulate corticotrophin-releasing hormone $(\mathrm{CRH})$ and arginine vasopressin (AVP) secretion from the paraventricular nucleus (PVN) (data amalgamated from observations in ewes and rats). The comma-shaped object represents CRH-AVP or GnRH neurones; the grey shaded rectangular areas denote different portions of the brain stem (A1 and A2 regions, the area postrema (AP) and the locus coeruleus (LC)) and the yellow areas indicate regions in the hypothalamus (medial preoptic area (MPOA), ventral medial nucleus $(\mathrm{VMN})$ and the arcuate nucleus (ARC) of the medial basal hypothalamus). The blast shapes represent neurones containing specific neurotransmitters (noradrenaline (NA), neuropeptide $Y$ (NPY), glutamate (GLUT), N-methyl-D-aspartate (NMDA), gamma amino butyric acid (GABA), endogenous opioid (EOP) and dopamine (DA)). The presence of receptors for oestradiol (ER) is indicated on appropriate neurones. The presence of receptors for $\mathrm{CRH}$, gamma amino butyric acid (GABA) or glucocorticoids (CRH-R, GABA-R or GR) are indicated on appropriate neurones. The interlinking red lines between areas of the brain represent known direct axons. There are axons from $\mathrm{GnRH}$ and CRH-AVP cells to the median eminence but these have been omitted here for clarity.

the LC increases the neuronal firing rate in this region and increases the release of noradrenaline in areas receiving projections from the LC (Fig. 5). Indeed, there is evidence to show that, in response to a variety of stressors, there is a cascade relationship between noradrenaline and $\mathrm{CRH}$ secretion in all areas containing $\mathrm{CRH}$ perikarya, that is the LC, CeA, BNST, MPOA and PVN (Koob, 1999). Thus, $\mathrm{CRH}$, as a neurotransmitter, may enhance activation of the HPA as well as being involved in final ACTH output.

\section{Reproductive hormone profiles during disruption by stressors}

After presenting individual HPO and HPA control mechanisms, changes in reproductive hormone profiles during exposure to stress will be examined, and this is followed by a discussion of the interactions involved within the brain.

\section{Effects of stressors on tonic GnRH-LH pulsatile secretion}

There are now many examples of gonadectomized animals (male and female) exhibiting a reduction in $\mathrm{GnRH}$ and hence LH pulsatility within 5-10 min of exposure to stress (Fig. 2a) indicating non-genomic effects on membrane polarization of interneurones (Fig. 2). It is difficult to ascertain from the available literature whether there are differences between stressors in their effects on pulse frequency or amplitude; if frequency of $\mathrm{GnRH}$ pulses is reduced, this may indirectly affect 
amplitude because basal values will differ. The use by different laboratories of different steroid treatments before exposure to stress also complicates the issue. Furthermore, most studies have used LH measurements to reflect changes in $\mathrm{GnRH}$, but it is now known that not all $\mathrm{GnRH}$ pulses are accompanied by $\mathrm{LH}$ secretion. However, changes in frequency do indicate a major effect at the hypothalamus. Indeed, the frequency, but not the amplitude or duration, of hypothalamic multi-unit electrical activity is decreased in stressed goats compared with controls (Takeuchi et al., 1997).

In rats, adrenaline modulates LH frequency, whereas noradrenaline affects both frequency and amplitude (Smith and Jennes, 2001). By comparison, in nonstressed sheep, GABA neurones control pulse frequency, whereas noradrenaline and opioid neurones mediate changes in pulse amplitude (Scott and Clarke, 1993; Goodman et al., 1995, 1996). As CRH predominates during 'weak' stressors and additional AVP is secreted during more intense stress (Caraty et al., 1990), it is possible that $\mathrm{CRH}$ affects pulse frequency via GABAnoradrenaline neurones, whereas AVP responses involve opioidergic cells, particularly as, in rats, i.c.v. AVP affects pulse amplitude but not frequency (Cates et al., 1999). This speculation urgently requires testing under closely controlled conditions by measuring $\mathrm{GnRH}$ in portal blood and by histochemical examination of multilabelled tissues.

\section{Effects of stress on GnRH-LH surge secretion}

Acute stressors can also interrupt the occurrence of a normal GnRH-LH surge during spontaneous follicular phases in intact ewes and in steroid-treated ovariectomized animals (Fig. 2a). After exposure to the severe stressors of endotoxin or high dose insulin during the activation phase, the onset of the $\mathrm{LH}$ surge is delayed by approximately $10 \mathrm{~h}$. Later, during the transmission phase, endotoxin has no effect on timing or other surge parameters. However, the onset is delayed by insulin and surge maximum concentrations are lower. Even the lesser stress of transport delays and reduces the magnitude of the LH surge when imposed during the late transmission or surge onset periods (Smith et al., in press).

The influence of stressors at the pituitary gland has been revealed by the reduced secretion of $\mathrm{LH}$ in response to $\mathrm{GnRH}$, both in vivo and in vitro (Phogat et al., 1999), and could be one explanation for reduced maximum surge values. Reduced surge concentrations probably relate to the importance of pulsatile $\mathrm{GnRH}$ in maintaining the pituitary gland in a primed state. In addition, continued oestradiol exposure is curtailed during $\mathrm{ACTH}$-induced reduction in $\mathrm{LH}$ pulsatility in the follicular phase, and this will have consequences at both the hypothalamus and pituitary gland (Dobson et al., 2000b).

\section{Mechanisms of interactions between HPA and HPO within the brain}

Stress-induced changes in reproductive hormone profiles are the result of altered neurotransmitter activities mediated by different neurones in several locations.

\section{Mediation by $C R H$ and AVP}

As the PVN is activated in all stressful situations, both $\mathrm{CRH}$ and AVP are prime candidates as mediators of reduced GnRH secretion. Indeed, $\mathrm{CRH}$ receptors have been identified on $\mathrm{GnRH}$ perikarya in rat immortal cell lines (Tellam et al., 2000; Fig. 5). Furthermore, administration of $\mathrm{CRH}$ or AVP either i.c.v. or directly into the MPOA (but not the PVN, ARC or ME) reduces $\mathrm{GnRH}$ secretion in rats or monkeys, and reversal of the effect by naloxone indicates opioid involvement (for reviews, see Rivier and Rivest, 1991; Phogat et al., 1997). Reversal of the CRH-AVP-induced suppression of $\mathrm{GnRH}$ by prior oestradiol treatment in monkeys indicates that the influence of steroids is balanced in different ways in different species, or that there is an oestradiol dose effect (Chen et al., 1992).

Confusingly, in sheep, i.c.v. CRH administration or exposure to transport can increase $\mathrm{GnRH}-\mathrm{LH}$ output, but only during periods of oestradiol negative feedback (Caraty et al., 1997; Dobson et al., 1999). This finding could be the result of neurotransmitter action unconnected to the stress axis, or steroid feedback mechanisms may be important. As a further complication, restraint of $\mathrm{CRH}$ knockout mice also decreases pulsatile and surge $\mathrm{LH}$ secretion indicating the presence of an opioid or AVP compensation mechanism. The importance of an AVP mechanism is emphasized by the fact that insulin has no effect on LH pulsatility in Brattleborough rats (a strain in which AVP is absent). More evidence lies in the inability of the antagonist helical CRH always to reverse the effects of $\mathrm{CRH}$ on $\mathrm{LH}$ release (Jeong et al., 1999). Most of these observations can be explained by a co-operative compensatory system between $\mathrm{CRH}$ and AVP. One further major factor to be taken into account is that destruction of the PVN does not obliterate the suppression of LH pulsatility during stress (Rivier and Rivest, 1991). Therefore, effects in rats must be mediated at least in part by pathways other than via the PVN, for example, via the CeA or the BNST (Koob, 1999).

\section{Interactions between the MPOA, PVN and the brain stem}

Several neuronal interactions, direct or indirect, have been recognized between the MPOA and the PVN (Fig. 5). There are CRH perikarya in the MPOA and synapses occur in the MPOA between GnRH neurones and $\mathrm{CRH}$-positive axons and AVP-positive axons, both of 
unidentified origin in rats, monkeys and goats (MacLusky et al., 1988; Thind and Goldsmith, 1988; Kikusui et al., 1997). In addition, CRH neurones from the PVN project to GABA cells in the MPOA (Cullinan, 2000). Thus, indirect mechanisms operate by provoking activity in the PVN and hence increasing delivery of $\mathrm{CRH}$ to the MPOA. For example, the PVN receives neuronal inputs from many nuclei (Fig. 5): noradrenaline-neuropeptide Y projections containing oestradiol receptors from the regions A1 and A2; dopamine neurones from the area postrema (part of the VLM activated by glucose availability and other stressors); GABA neurones from the MPOA; and neuropeptide $Y$ axons from the ARC. Indirectly, catecholaminergic neurones from the $A 1$ region synapse in the MPOA with neuropeptide $\mathrm{Y}$-noradrenaline afferent neurones projecting to the PVN (Kawano and Masuko, 1999, 2000).

The significance of the increased PVN influence on MPOA activity is revealed by the stress-induced concurrent activation of $\mathrm{CRH}$ neurones in the PVN and the reduction in the number of $\mathrm{GnRH}$ cells expressing $c$-fos within the MPOA, both during the period when $\mathrm{GnRH}-\mathrm{LH}$ secretion declines (Briski and Sylvester, 1998). Most of the above observations are from rats and, again, it is imperative to have confirmation in another species that does not positively associate increased adrenal activity with the onset of the $\mathrm{GnRH}-\mathrm{LH}$ surge.

\section{Mediation by suppressive opioids and GABA, or stimulatory neuropeptide $Y$ and serotonin}

The influence of opioid mediation in stress-induced GnRH suppression is revealed by the ability of naloxone to reverse the decrease in pulse frequency after restraint, injection of 2-deoxy-glucose (2DG; to rapidly lower glucose availability) or insulin administration in sheep or rats, but not in monkeys (Clarke et al., 1990; Chen et al., 1992; Cagampang et al., 1997). Insulin-induced delays in the LH surge in sheep are also reversed by naloxone, whereas the progesterone receptor antagonist, RU486, is unable to bring forward the delayed $\mathrm{LH}$ surge (Dobson and Smith, 2000). As there is an increase in mRNA encoding pro-opiomelanocortin (POMC) in the ARC after glucoprivation in rats, all these effects are probably mediated by opioid influence from the ARC via synapses in the MPOA. These opioid synapses occur both with noradrenaline-neuropeptide $\mathrm{Y}$ projections from the MPOA to the PVN, and with $\mathrm{CRH}$ axons from the PVN to the MPOA (Kawano and Masuko, 1999, 2000). Local opioid antagonists are effective in reversing decreased GnRH-LH pulsatility only when applied in the MPOA and not the ARC, emphasizing that it is the MPOA that is the actual site of action. Furthermore, naloxone also reverses the decline in the number of $\mathrm{GnRH}$ neurones recruited in the MPOA after treatment of oestradiol-sensitized ovariectomized rats with 2DG
(Briski and Sylvester, 1998). The opioid-induced low recruitment of $\mathrm{GnRH}$ neurones during stress probably interferes with synchronized firing of $\mathrm{GnRH}$ neurones, leading to disrupted LH secretion (Goodman et al., 1995).

Suppressive GABA neurones have been implicated in stress-induced reductions in $\mathrm{GnRH}$ secretion. During chronic stress, concentrations of mRNA encoding GABA increase in the MPOA and BNST. Apart from a direct effect on GnRH neurones, as part of a negative feedback system, high GABA concentrations could exert influence via the above mentioned neuronal pathways to downregulate CRH-AVP activity in the PVN (Fig. 5). There are GABA receptors on $95 \%$ of $\mathrm{CRH}$ neurones in the PVN (Cullinan, 2000). Furthermore, GABA injected directly into the PVN or $\mathrm{MBH}$ decreases $\mathrm{CRH}$ and, conversely, GABA antagonists administered into the PVN increase CRH-AVP (Cole and Sawchenko, 2002). Indeed, insulin-induced effects on LH pulse frequency and amplitude are reversed in monkeys by the GABA receptor antagonist, alprazolam (van Vugt et al., 1997). Therefore, it is clear the GABA is involved in the suppression of LH secretion (Fig. 2b) but future work is needed to examine more closely the simultaneous effects of stressors on GABA and $\mathrm{GnRH}$ neurone activity.

Stimulatory neuropeptide $\mathrm{Y}$ may have an indirect effect during stress-induced reductions in LH pulsatility. Insulin treatment increases neuropeptide $\mathrm{Y}$ in the ARC and PVN (Fig. 5), and administration of neuropeptide $Y$ stimulates $\mathrm{CRH}$ release thus increasing peripheral opioid, ACTH and corticoid secretion (Porter et al., 1993; Krysiak et al., 1999). Furthermore, the decline in LH pulsatility after neuropeptide $\mathrm{Y}$ administration in rats is regulated by the prevailing steroid milieu, possibly as a result of oestradiol-mediated increased opioid influence. There are neuropeptide $\mathrm{Y}$ perikarya in the ARC with projections to the PVN (Fig. 5), but it has not been established whether they are part of the $15 \%$ of the neuropeptide $Y$ population with oestradiol receptors (Clarke et al., 2001). However, in the breeding season of sheep, administration of neuropeptide $\mathrm{Y}$ into the third ventricle has no effect on LH pulsatility in the presence or absence of oestradiol, although peripheral concentrations of cortisol increase (Porter et al., 1993). Further studies are required to establish the precise role of neuropeptide $\mathrm{Y}$ in stressinduced reductions of $\mathrm{GnRH}-\mathrm{LH}$ secretion.

With respect to serotonin, the possible involvement of the Raphe nuclei in the brain stem is revealed by the existence of $\mathrm{CRH}$ neurones that innervate this area where there are also $\mathrm{CRH}$ receptors. Administration of $\mathrm{CRH}$ inhibits serotonin release and Raphe neuronal activity (Price et al., 1998). Serotonergic axons from the Raphe nuclei also project into the MPOA to enhance $\mathrm{GnRH}$ secretion (Smith and Jennes, 2001), and so the MPOA could be influenced by the stress-induced reduction in serotonin activity. 
Influence of oestradiol on stress-induced suppression of GnRH-LH secretion

The effects of stressors on $\mathrm{GnRH}-\mathrm{LH}$ secretion are intensified by gonadal steroids (oestradiol in females and testosterone in males), although conversion of testosterone to oestradiol is likely in males (Maeda et al., 1994; Adam and Findlay, 1998; Tilbrook et al., 2000). The sex steroids modify CRH transcription and expression (Tellam et al., 2000), and CRH neurones have been identified in the MPOA in different species (see above). Indeed, in a series of elegant experiments, K-I. Maeda's group showed that oestradiol treatment sensitizes LH secretion to suppression by stressors (glucoprivation, fasting or immobilization) at doses that do not change the characteristic LH pulsatility pattern in ovariectomized rats. Catecholamines increase the number of oestradiol receptors in the hypothalamus, and this has implications for the interaction between stress and $\mathrm{GnRH}-\mathrm{LH}$ suppression. Stress-induced noradrenaline suppression of LH pulse frequency is enhanced by oestradiol, but only by localized action in the PVN or A1-A2 regions and not in the MPOA or ARC (Fig. 4; Maeda et al., 1994; Nagatani et al., 1996; Cagampang et al., 1997). Indeed, during stress, the number of noradrenalinedopamine cells with oestradiol receptors increases in the PVN and brainstem (A1 and A2 regions) but not in the MPOA, ARC or VMN (Estacio et al., 1996; Reyes et al., 2001). Furthermore, $\alpha$-helical CRH will reverse the effects of stressors on LH pulse frequency and amplitude in oestradiol-sensitized rats, whereas i.c.v. AVP only reduces LH pulse amplitude (Cates et al., 1999). There is an oestrogen response element on the mRNA encoding $\mathrm{CRH}$ and an increase in this CRH mRNA occurs in the PVN after oestradiol treatment late in pro-oestrus (Herbison, 1998). Thus, there is a distinct modulating effect of oestradiol on neurotransmitter activity during stress. Again, observations must be interpreted with care in rats because of the corticoid-induced $\mathrm{LH}$ surge late in pro-oestrus in this species.

\section{Other aspects of HPO and HPA interactions}

Although GnRH cell bodies are most abundant in the MPOA in rats, a small population of uncertain function has been identified in the ARC in sheep. The efferent axons of both MPOA and ARC populations project into the ME close to the hypophyseal portal blood capillaries. There are receptors for noradrenaline, glutamine or neuropeptide $Y$ at the efferent axon-capillary junction but it is thought that these neurotransmitters have minimal pre-synaptic control of $\mathrm{GnRH}$ release in the $\mathrm{ME}$ (Smith and Jennes, 2001). Furthermore, CRH neurones are not associated with GnRH rich areas in the ME. However, it is possible that changes occur in glial cell ensheathment and tanycyte architecture. These cells encasing $\mathrm{GnRH}$ neurones might prevent axon terminals temporarily forming synapses with the portal capillaries. Equally, glial changes in the ARC and MPOA are associated with regulation of $\mathrm{GnRH}$ release. The presence of oestradiol receptors and structural changes within $5 \mathrm{~h}$ of oestradiol treatment indicate an involvement in reproduction but stress-associated changes still require elucidation (Herbison, 1998; Viguie et al., 2001).

All stressors result in increases in corticoids and catecholamines from the adrenal gland medulla but it is unlikely that these have a major influence on $\mathrm{LH}$ secretion because stress effects on $\mathrm{GnRH}$ have been observed in adrenalectomized animals (Rivier and Rivest, 1991). Furthermore, peripheral catecholamines or cortisol may not cross the blood-brain barrier (Deaver and Dailey, 1982; Adam and Findlay, 1998). Nevertheless, prolactin and cortisol have been associated with suppression of transcription of the $\mathrm{GnRH}$ promoter in rats (Tellam et al., 2000). In sheep, prolonged highdose cortisol infusions interfere with $\mathrm{LH}$ pulses and surge secretion but, confusingly, inhibition of cortisol synthesis by metyrapone does not inhibit endotoxininduced suppression of LH release (MacFarlane et al., 2000; Karsch et al., 2002).

\section{Conclusions}

In normal intact animals, oestradiol activation of $\mathrm{GnRH}-$ LH surge secretion involves an initial stimulatory oestradiol signal but restraining modulation is mediated by noradrenaline and opioid regulation of suppressive GABA neurones. During the later transmission phase in which oestradiol concentrations are higher, a gradual removal of opioid influence may mediate the uncoupling of noradrenaline restraint on GABA cells, resulting in a (now oestradiol-independent) more positive noradrenaline influence on $\mathrm{GnRH}-\mathrm{LH}$ release. The concomitant overall increase in $\mathrm{GnRH}$ secretion, along with further increased oestradiol, enhances synthesis of $\mathrm{GnRH}$ receptors and LH $\beta$ in the pituitary gland. At the end of the transmission phase, neurotransmitters control the recruitment of more $\mathrm{GnRH}$ neurones, culminating in coordinated hyperpolarization and massive outpouring of $\mathrm{GnRH}$ into the portal capillaries to cause secretion of the prepared stores of $\mathrm{LH}$. Depending on the intensity, stress impedes the activation or transmission phases, or both, by stimulation of oestradiol-sensitive PVN activity that interferes with GnRH neurone recruitment, and hence GnRH pulsatility decreases and surge secretion is disrupted. Several reproductive situations involve suppression of $\mathrm{GnRH}-\mathrm{LH}$ pulsatility mediated by increased sensitivity to oestradiol in different parts of the hypothalamus and brain stem. For example, seasonality involves the A14 and $\mathrm{A} 15$ regions, whereas undernutrition, fasting or other stressors involve the area postrema of the $\mathrm{A} 1$ region of the brain stem in collaboration with the PVN and possibly the CeA. 
Therefore, in terms of human and animal fertility, how important are changes $\mathrm{GnRH}-\mathrm{LH}$ pulse frequency and amplitude, oestradiol profiles and the precise timing of events leading up to the LH surge? During maturation, gametes are closely associated with steroid-producing support cells (Leydig cells in the testis or ovarian follicular granulosa cells). Interruption of LH pulsatility (by GnRH antagonists or by stressors) in the follicular phase lowers oestradiol production and reduces the subsequent rate of blastocyst formation (Dobson and Smith, 1998; Oussaid et al., 1999). Oestradiol is also required for expression of behavioural oestrus, along with increased $\mathrm{GnRH}$ concentrations in the hypothalamus (Caraty et al., 2002). Furthermore, increased $\mathrm{CRH}$ has behavioural effects that appear to be independent of the pituitary-adrenal axis, for example, i.c.v. administration of $\mathrm{CRH}$ decreases food intake and sexual behaviour in oestrogen-primed rats (Koob, 1999).

Delayed LH surges and the resulting extended follicular phases are deleterious to fertility (Dobson and Smith, 2000). Indeed, cows with 'production diseases' such as hypocalcaemia, dystocia, ketosis or lameness are less fertile, possessing smaller follicles than healthy herd-mates in the breeding period approximately 6 weeks after calving (W. J. Clarke, H. Dobson and R. F. Smith, unpublished). These smaller follicles could be the result of lowered LH pulse frequency or stressmediated interference with gonadotrophin recruitment of early follicles. Similar studies on human patients with anxiety driven subfertility would be of interest.

The authors are grateful to all past and present postgraduate students and postdoctoral fellows that have worked in the Reproduction Stress research group at Leahurst, as well as the technical skills of J. Routley, H. Pursell and N. Jones. This review would not have been possible without their active support.

\section{References}

Key references are identified by asterisks.

Adam CL and Findlay PA (1998) Inhibition of luteinizing hormone secretion and expression of c-fos and corticotrophin-releasing factor genes in the paraventricular nucleus during insulin-induced hypoglycaemia in sheep Journal of Neuroendocrinology 10 777-783

Anderson ST, Walsh JP, Tillet Y, Clarke IJ and Curlewis JD (2001) Dopaminergic input to the ventromedial hypothalamus facilitates the oestrogeninduced luteinizing hormone surge in ewes Neuroendocrinology $\mathbf{7 3}$ 91-101

Briski KP and Sylvester PW (1998) Role of endogenous opiates in glucoprivic inhibition of the luteinizing hormone surge and Fos expression by preoptic gonadotropin-releasing hormone neurones in ovariectomized steroid-primed female rats Journal of Neuroendocrinology 10 769-776

Brooks J and McNeilly AS (1996) Regulation of gonadotrophin-releasing hormone receptor expression in the ewe Animal Reproduction Science 42 89-98

Cagampang FRA, Cates PS, Sandhu S, Strutton PH, McGarvey C, Coen CW and O'Byrne KT (1997) Hypoglycaemia-induced inhibition of pulsatile luteinizing hormone secretion in female rats: role of oestradiol, endogenous opioids and the adrenal medulla Journal of Neuroendocrinology 9 867-872

Caraty A, Grino M, Locatelli A, Guillaume V, Boudouresque F, Conte-
Devolx B and Oliver C (1990) Insulin-induced hypoglycemia stimulates corticotropin-releasing factor and arginine vasopressin secretion into hypophysial portal blood of conscious, unrestrained rams Journal of Clinical Investigation 85 1716-1721

Caraty A, Miller DW, Delaleu B and Martin GB (1997) Stimulation of LH secretion in sheep by central administration of corticotrophin-releasing hormone Journal of Reproduction and Fertility 111 249-257

Caraty A, Delaleu B, Chesneau D and Fabre-Nys C (2002) Sequential role of $E_{2}$ and $\mathrm{GnRH}$ for the expression of estrous behavior in ewes Endocrinology 143 139-145

Cates PS, Forsling ML and O'Byrne KT (1999) Stress-induced suppression of pulsatile LH release in the female rat: role of vasopressin Journal of Neuroendocrinology 11 677-683

Chen MD, O'Byrne KT, Chiappini SE, Hotchkis J and Knobil E (1992) Hypoglycemic stress and gonadotropin-releasing hormone pulse-generator activity in the rhesus monkey - role of the ovary Neuroendocrinology 56 666-673

Clarke IJ, Horton RJE and Doughton BW (1990) Investigation of the mechanism by which insulin-induces hypoglycaemia decreases LH secretion in ovariectomised ewes Endocrinology $127 \quad 1470$ 1476

Clarke IJ, Pompolo S, Scott CJ, Rawson JA, Caddy D, Jakubowska AE and Pereira AM (2001) Cells of the arcuate nucleus and ventromedial nucleus of the ovariectomized ewe that respond to oestrogen: a study using Fos immunohistochemistry Journal of Neuroendocrinology $\mathbf{1 3}$ 934-941

Cole RAL and Sawchenko PE (2002) Neurotransmitter regulation of cellular activation and neuropeptide gene expression in the paraventricular nucleus of the hypothalamus Journal of Neuroscience 22959 969

Cullinan WE (2000) GABA(A) receptor subunit expression within hypophysiotropic CRH neurons: a dual hybridization histochemical study Journal of Comparative Neurology 419 344-351

Deaver R and Dailey CE (1982) Effects of DA, NE and serotonin on plasma concentrations of $\mathrm{LH}$ and prolactin in ovariectomised and anestrous ewes Biology of Reproduction 27 624-632

Dobson H and Smith RF (1998) Stress and subfertility Reproduction In Domestic Animals 33 107-111

*Dobson H and Smith RF (2000) What is stress, and how does it affect reproduction? Animal Reproduction Science 60 743-752

Dobson H, Tebble JE, Ozturk M and Smith RF (1999) Effect of transport on pulsatile LH release in ovariectomized ewes with or without prior steroid exposure at different times of year Journal of Reproduction and Fertility 117 213-222

Dobson H, Tebble JE and Smith RF (2000a) Effect of naloxone or RU486 on an insulin-induced delay of the LH surge in intact ewes Journal of Reproduction and Fertility Abstract Series $\mathbf{2 7} 6$

Dobson H, Ribadu AY, Noble KM, Tebble JE and Ward WR (2000b) UItrasonography and hormone profiles of adrenocorticotrophic hormone (ACTH)-induced persistent ovarian follicles (cysts) in cattle Journal of Reproduction and Fertility 120 405-410

Estacio MAC, Yamada S, Tsukamura H, Hirunagi K and Maeda KI (1996) Effect of fasting and immobilization stress on estrogen receptor immunoreactivity in the brain in ovariectomized female rats Brain Research 717 55-61

Evans NP, Dahl GE, Mauger DT, Padmanabhan V, Thrun LA and Karsch FJ (1995) Does estradiol induce the preovulatory GnRH surge in the ewe by inducing a progressive change in the mode of operation by the $\mathrm{GnRH}$ neurosecretory system? Endocrinology 136 5511-5519

Evans NP, Dahl GE, Padmanabhan V, Thrun LA and Karsch FJ (1997) Estradiol requirements for induction and maintenance of the gonadotropin-releasing hormone surge: implications for neuroendocrine processing of the estradiol signal Endocrinology 138 54085414

Goodman RL, Parfitt DB, Evans NP, Dahl GH and Karsch FJ (1995) Endogenous opioid-peptides control the amplitude and shape of gonadotropin-releasing hormone pulses in the ewe Endocrinology 136 $2412-2420$ 
Goodman RL, Havern RL and Whisnant CS (1996) Alpha adrenergic neurons inhibit luteinizing hormone pulse amplitude in breeding season ewes Biology of Reproduction 54 380-386

Goubillon ML, Delaleu B, Tillet Y, Caraty A and Herbison AE (1999) Localization of estrogen-receptive neurons projecting to the $\mathrm{GnRH}$ neuron-containing rostral preoptic area of the ewe Neuroendocrinology 70 228-236

Goubillon ML, Caraty A and Herbison AE (2002) Evidence in favour of a direct input from the ventromedial nucleus to gonadotropin-releasing hormone neurones in the ewe: an anterograde tracing study Journal of Neuroendocrinology 14 95-100

Hamernik DL (1995) Molecular biology of gonadotrophins Journal of Reproduction and Fertility Supplement 49 257-269

Heisler LE, Tumber AJ, Reid RL and van Vugt DA (1994) Vasopressin mediates hypoglycemia-induced inhibition of luteinizing hormone secretion in the ovariectomized rhesus monkey Neuroendocrinology 60 297-304

Herbison AE (1997) Noradrenergic regulation of cyclic GnRH secretion Reviews of Reproduction 2 1-6

*Herbison AE (1998) Multimodal influence of estrogen upon gonadotropinreleasing hormone neurons Endocrine Reviews 19 302-330

Jeong KH, Jacobson L, Widmaier EP and Majzoub JA (1999) Normal suppression of the reproductive axis following stress in $\mathrm{CRH}$-deficient mice Endocrinology 140 1702-1708

Jimenez-Linman M and Rubin BS (2001) Dynamic changes in LHRH transcriptional activity are associated with the steroid-induced $\mathrm{LH}$ surge Brain Research 922 71-79

Karsch FJ and Evans NP (1996) Feedback actions of estradiol on $\mathrm{GnRH}$ secretion during the follicular phase of the estrous cycle Acta Neurobiologiae Experimentalis 56 715-725

Karsch FJ, Battaglia DF, Breen KM, Debus N and Harris TG (2002) Mechanisms for ovarian cycle disruption by immune/inflammatory stress Stress 5 101-112

Kawano H and Masuko S (1999) Synaptic contacts between nerve terminals originating from the ventrolateral medullary catecholaminergic area and median preoptic neurons projecting to the paraventricular hypothalamic nucleus Brain Research 817 110-116

Kawano H and Masuko S (2000) Beta-endorphin-, adrenocorticotrophic hormone- and neuropeptide $\mathrm{Y}$-containing projection fibers from the arcuate hypothalamic nucleus make synaptic contacts on to nucleus preopticus medianus neurons projecting to the paraventricular hypothalamic nucleus in the rat Neuroscience 98555 565

Kikusui T, Takeuchi Y and Mori Y (1997) Immunohistochemical localization of corticotropin-releasing factor, [arginine(8)]-vasopressin and oxytocin neurons in the goat hypothalamus Journal of Veterinary Medical Science $59621-628$

*Koob GF (1999) Corticotropin-releasing factor, norepinephrine, and stress Biology of Psychiatry 46 1167-1180

Krysiak R, Obuchowicz E and Herman ZS (1999) Interactions between the neuropeptide $Y$ system and the hypothalamic-pituitary-adrenal axis European Journal of Endocrinology 140 130-269

McFarlane A, Coghlan J, Tresham J and Wintour EM (1995) Corticotropinreleasing factor alone, but not arginine-vasopressin alone, stimulates the release of adrenocorticotropin in the conscious intact sheep Endocrinology 136 1821-1827

MacFarlane MS, Breen KM, Sakurai H, Adams BM and Adams TE (2000) Effect of duration of infusion of stress-like concentrations of cortisol on follicular development and the preovulatory surge of LH in sheep Animal Reproduction Science 63 167-175

MacLusky NJ, Naftolin F and Leranth C (1988) Immunocytochemical evidence for direct synaptic connections between corticotrophinreleasing factor (CRF) and gonadotropin-releasing hormone (GNRH)containing neurons in the preoptic area of the rat Brain Research 439 391-395

Maeda KI, Cagampang FRA, Coen CW and Tsukamura H (1994) Involvement of the catecholaminergic input to the paraventricular nucleus and of corticotropin-releasing hormone in the fasting-induced suppression of luteinizing-hormone release in female rats Endocrinology 134 1718-1722

Nagatani S, Tsukamura H, Murahashi K, Bucholtz DC, Foster DL and Maeda KI (1996) Paraventricular norepinephrine release mediates glucoprivic suppression of pulsatile luteinizing hormone secretion Endocrinology 137 3183-3186

Narayana K and Dobson H (1979) Alpha-adrenergic control of gonadotrophin secretion in the ewe Journal of Veterinary Pharmacology and Therapeutics 2 47-57

Oussaid B, Mariana JC, Poulin N, Fontaine J, Lonergan P, Beckers JF and Cognie $\mathbf{Y}$ (1999) Reduction of the developmental competence of sheep oocytes by inhibition of LH pulses during the follicular phase with a GnRH antagonist Journal of Reproduction and Fertility 117 71-77

Phogat PB, Smith RF and Dobson H (1997) The influence of stress on neuroendocrine control of the hypothalamic-pituitary-ovarian axis Veterinary Bulletin 67 553-567

Phogat PB, Smith RF and Dobson H (1999) Effect of adrenocorticotrophic hormone $\left(\mathrm{ACTH}^{1-24}\right)$ on ovine pituitary gland responsiveness to exogenous pulsatile GnRH and oestradiol-induced $\mathrm{LH}$ release in vivo. Animal Reproduction Science 55 193-203

Porter DWF, Naylor AM, McNeilly AS and Lincoln DW (1993) Endocrine actions of central neuropeptide $\mathrm{Y}$ in the ewe - activation of the hypothalamo-pituitary-adrenal axis by exogenous neuropeptide $\mathrm{Y}$ and role of endogenous neuropeptide $\mathrm{Y}$ in the secretion of luteinizinghormone during the estrous-cycle Journal of Neuroendocrinology 5163 174

Price ML, Curtis AL, Kirby LG, Valentino RJ and Lucki I (1998) Effects of corticotrophin-releasing factor on brain serotonergic activity Neuropsychopharmacology 18 492-502

Rawson JA, Scott CJ, Pereira A, Jakubowska A and Clarke IJ (2001) Noradrenergic projections from the A1 field to the preoptic area in the brain of the ewe and Fos responses to oestrogen in the A1 cells Journal of Neuroendocrinology 13 129-138

Reyes BAS, Estacio MAC, I'Anson H, Tsukamura H and Maeda KI (2001) Glucoprivation increases estrogen receptor alpha immunoreactivity in the brain catecholaminergic neurons in ovariectomized rats Neuroscience Letters 299 109-112

*Rivier C and Rivest S (1991) Effect of stress on the activity of the hypothalamic-pituitary-gonadal axis - peripheral and central mechanisms Biology of Reproduction 45 523-532

Robinson JE, Kendrick KM and Lambart CE (1991) Changes in the release of gamma-aminobutyric-acid and catecholamines in the preoptic septal area prior to and during the preovulatory surge of $\mathrm{LH}$ in the ewe Journal of Neuroendocrinology 3 393-399

Scott CJ and Clarke IJ (1993) Inhibition of luteinizing-hormone secretion in ovariectomized ewes during the breeding-season by gammaaminobutyric-acid (GABA) is mediated by GABA-A receptors, but not GABA-B receptors Endocrinology 132 1789-1796

Scott CJ, Cummins JT and Clarke IJ (1992) Effects on plasma LH levels of microinjection of noradrenaline and adrenaline into the septo-preoptic area of the brain of the ovariectomised ewe: changes with season and chronic oestrogen treatment Journal of Neuroendocrinology 4 131-141

Scott CJ, Rawson JA, Pereira AM and Clarke IJ (1999) Oestrogen receptors in the brainstem of the female sheep: relationship to noradrenergic cells and cells projecting to the medial preoptic area Journal of Neuroendocrinology 11 745-756

Smith MJ and Jennes L (2001) Neural signals that regulate GnRH neurones directly during the oestrous cycle Reproduction 122 1-10

Smith RF, Ghuman SPS, Evans NP, Karsch FJ and Dobson H Stress and the control of $\mathrm{LH}$ secretion in the follicular phases of ewes Reproduction Supplement $\mathbf{6 1}$ (in press)

Takeuchi Y, Nagabukuro H, Kizumi O and Mori Y (1997) Lipopolysaccharide-induced suppression of the hypothalamic gonadotropin-releasing hormone pulse generator in ovariectomized goats Journal of Veterinary Medical Science 59 93-96

*Tellam DJ, Mohammad YN and Lovejoy DA (2000) Molecular integration 
of hypothalamo-pituitary-adrenal axis-related neurohormones on the GnRH neuron Biochemistry and Cell Biology 78 205-216

Thind KK and Goldsmith PC (1988) Infundibular gonadotropin-releasing hormone neurons are inhibited by direct opioid and autoregulatory synapses in juvenile monkeys Neuroendocrinology $47203-$ 216

Tilbrook AJ, Turner AI and Clarke IJ (2000) Effects of stress on reproduction in non-rodent mammals: the role of glucocorticoids and sex differences Reviews of Reproduction 5 105-113

van Vugt DA, Washburn DLS, Farley AE and Reid RL (1997) Hypoglycemiainduced inhibition of $\mathrm{LH}$ and stimulation of $\mathrm{ACTH}$ secretion in the
Rhesus monkey is blocked by Alprozam Neuroendocrinology 65344 352

Vazquez-Martinez R, Shorte SL, Faught WJ, Leaumont DC, Frawley LS and Boockfor C (2001) Pulsatile exocytosis is functionally associated with $\mathrm{GnRH}$ gene expression in immortalized $\mathrm{GnRH}$-expressing cells Endocrinology 142 5364-5370

Viguie C, Jansen HT, Glass JD, Watanabe M, Billings HJ, Coolen L, Lehman MN and Karsch FJ (2001) Potential for polysialylated form of neural cell adhesion molecule-mediated neuroplasticity within the gonadotropinreleasing hormone neurosecretory system of the ewe Endocrinology 142 1317-1324 